\title{
SBPMAT 2014 to be held September 28-October 2 in Brazil http://www.sbpmat.org.br/
}

$\mathrm{T}^{\mathrm{T}}$ he XIII Sociedade Brasileira de Pesquisa em Materiais (SBPMAT) 2014 Meeting will be held September 28-October 2, 2014, in João Pessoa, Brazil. It is chaired by Iêda Maria Garcia dos Santos and Severino Jackson Guedes de Lima, both of the Federal University of Paraíba, Brazil.

The Meeting features 19 symposia dedicated to recent advances and perspectives in materials science and technology. During the opening ceremony, José Arana Varela (São Paulo State University, Brazil) will present a memorial lecture on Joaquim Costa Ribeiro.

There are six plenary lecturers: Alberto Salleo (Stanford University,
USA) will speak on organic electronic devices; Roberto Dovesi (Università degli Studi di Torino, Italy) will address theoretical calculations applied to materials; Luís Antonio F.M. Dias Carlos (Universidade de Aveiro, Portugal) will talk about luminescence applied to nanomedicine; Jean Marie Dubois (Institut Jean Lamour, France) will lecture on quasicrystal materials; Sir Colin Humphreys (University of Cambridge, England) will speak on GaN and microscopy; and Karl Leo (King Abdullah University of Science and TechnologyKAUST, Saudi Arabia) will address KAUST's Solar and Photovoltaics Engineering Research Center.
Best works presented in each symposium, oral or poster, may be published as open access papers in a proceedings volume in the IOP Conference Series: Materials Science and Engineering. The best student works may apply for the Bernhard Gross Award.

Meeting Scene ${ }^{\circledR}$ e-newsletters featuring highlights of the Meeting will be produced daily. To subscribe, visit My MRS at http://www.mrs.org/mymrs/ and select Subscribe/Unsubscribe from MRS Newsletters and Alerts, or email info@mrs.org.

More information can be accessed from the meeting website at http://www.sbpmat. org.br/ or email 13encontro@sbpmat.org.br.

\section{E-MRS 2014 Fall Meeting to be held in September in Poland www.emrs-strasbourg.com}

$\mathrm{T}_{\mathrm{s} \text { sent }}$ he European Materials Research Society (E-MRS) 2014 Fall Meeting will be held September 15-19, 2014, at the Warsaw University of Technology, Poland. It is chaired by Bernard Gil (CNRS-University of Montpellier II, France), Jean-François Hochepied (ENSTA ParisTech UCP, France), Joerg K.N. Lindner (University of Paderborn, Germany), and Andrzej Mycielski (Institute of Physics, Polish Academy of Sciences, Poland).
The Meeting includes a plenary session, an exhibition, and 23 symposia organized into six categories: Nano Biomaterials, Nanomaterials and Nanotechnology, Semiconductor Materials and Spintronics, Oxide Materials, Advanced Functional Materials, and Materials Characterization.

Plenary speakers are Clément Sanchez (Collège de France, France), and Hidenori Takagi (Max Planck Institute for Solid State Research, Germany), and George M. Whitesides of Harvard University (USA), who received the 2014 Czochralski Award.

E-MRS and Sample of Science partnered to provide an event during the Meeting called "Sample Corner." This event offers opportunities for researchers to discuss collaborations, research projects, and an exchange of resources.

More information can be accessed at the meeting website at www.emrsstrasbourg.com or by emailing emrs@ emrs-strasbourg.com.

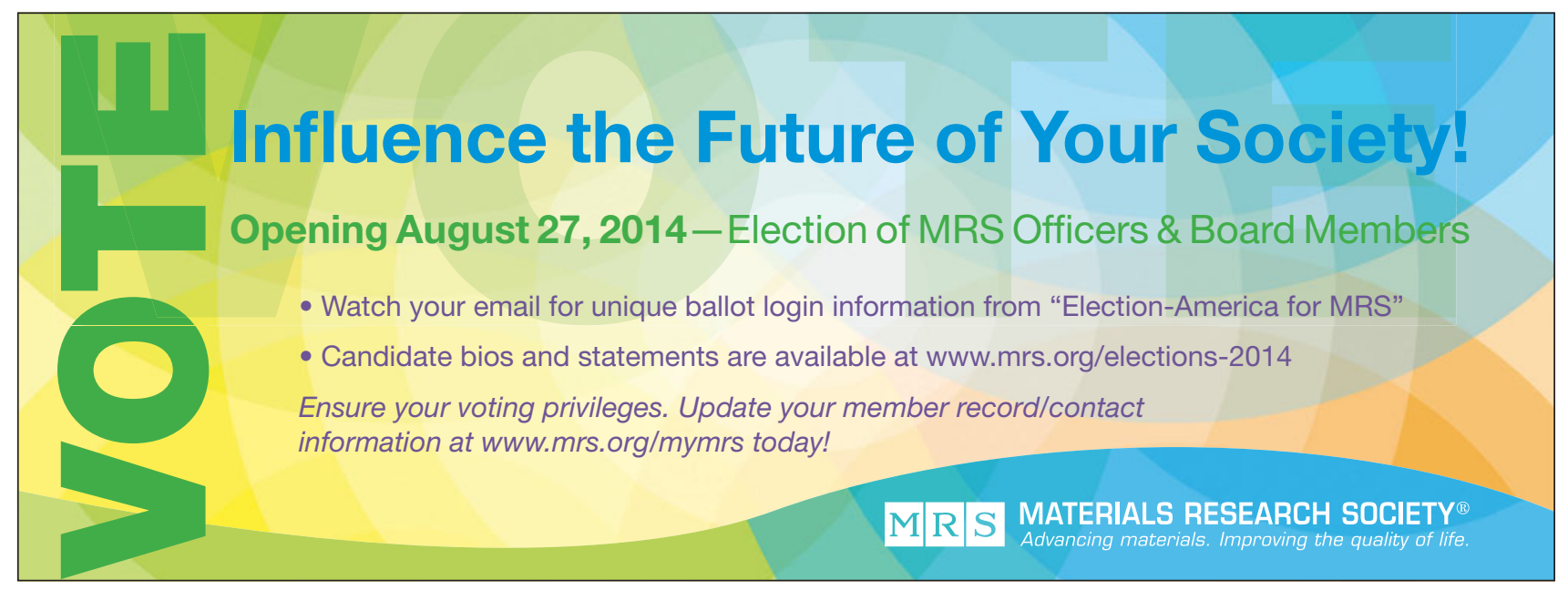

